\title{
Procedural Animation Method for Realistic Behavior Control of Artificial Fish
}

\author{
Kim Chong Han ${ }^{\dagger}$ Y Youn Jae Hong ${ }^{++} \cdot$ Kim Byung Ki ${ }^{+++}$
}

\begin{abstract}
In the virtual space with the interactive 3D contents, the degree of mental satisfaction is determined by how fully it reflect the real world. There are a few factors for getting the high completeness of virtual space. The first is the modeling technique with high-polygons and high-resolution textures which can heighten an visual effect. The second is the functionality. It is about how realistic represents dynamic actions between the virtual space and the user or the system. Although the studies on the techniques for animating and controlling the virtual characters have been continued, there are problems such that the long production time, the high cost, and the animation without expected behaviors. This paper suggest a method of behavior control of animation by designing the optimized skeleton which produces the movement of character and applying the procedural technique using physical law and mathematical analysis. The proposed method is free from the constraint on one-to-one correspondence rules, and reduce the production time by controlling the simple parameters, and to increase the degree of visual satisfaction.
\end{abstract}

Keywords : Procedual Animation, Virtural Space, Artificial Intelligent, Virtual Marine World, Sensory System

\section{절차적 애니메이션 방법을 이용한 인공물고기의 사실적 행동제어}

\author{
김 종 한 ${ }^{+} \cdot$ 윤 재 홍 ${ }^{++} \cdot$ 김 병 기 ${ }^{+++}$
}

\begin{abstract}
요 약
인터랙티브 3D 콘텐츠에서 가상공간은 현실세계를 얼마나 충분히 반영하느냐에 따라 사용자의 심리적 만족도가 결정된다. 완성도 높은 가 상공간을 표현하기 위해서는 몇 가지 요소가 필요하다. 첫째는 시각적 효과를 높이기 위해서 많은 폴리곤과 해상도 높은 텍스쳐를 이용한 모델 링 기법이다. 둘째는 기능상의 효과이다. 이것은 가상공간과 사용자 또는 시스템과의 인터랙션을 통한 동적 행위들이 얼마나 사실적으로 표현 되는가이다. 이를 위해 가상의 캐릭터에 대한 애니메이션 생성하고 행동을 제어 할 수 있는 기법에 대한 연구가 이루어져 왔으나 긴 제작 시간 또는 높은 비용이 소요되거나 원하는 행동을 생성하지 못하는 경우가 발생하는 문제점이 발견되어 왔다. 본 논문에서는 캐릭터의 동작을 생성 하는 최적화되어 있는 골격구조를 설계하고 물리법칙과 수학적 해석을 이용한 절차적 기법을 통해 인공물고기의 행동 제어하는 방법을 제시한 다. 이는 정해진 이벤트에 대해 반응하는 일대일 대응 규칙의 한계성에서 벗어나 간단한 파라미터의 조작을 통해 제작 시간을 단축하고 시각적 만족도를 높일 수 있을 것이다.
\end{abstract}

키워드 : 절차적 애니메이션, 가상공간, 인공지능, 가상수중환경, 센서시스템

\section{1. 서 론}

급속한 하드웨어의 발달로 높은 그래픽 품질을 표방하는 게임들이 물밀 듯이 쏟아져 나오고 있는 현재, 이에 익숙해 진 사용자들의 심미적 만족감을 충족하기 $3 \mathrm{D}$ 콘텐츠는 비 약적으로 발전하고 있다. 대개 일반적인 애니메이션 영화나

\footnotetext{
† 정 회 원:전남대학교 전산학과 박사과정

†† 정 회 원 : 동신대학교 디지털콘텐츠협동연구센터 부장

†† 종신회원 : 전남대학교 전자컴퓨터공학부 교수

논문접수: 2013년 5월 14일

수 정 일 : 1 차 2013년 6월 26일

심사완료 : 2013년 6월 26일

* Corresponding Author: Youn Jae Hong(jhyoun@dsu.ac.kr)
}

동영상 등의 캐릭터 생성할 때는 주로 숙련된 사용자가 $3 \mathrm{DsMax}$ 나 MAYA와 같은 전문 애니메이션툴을 사용하여 수작업으로 생성하는 경우가 많다. 캐릭터들의 자연스러운 움직임을 위해서는 많은 시간과 전문가의 노력이 요구된다. 이는 $3 \mathrm{D}$ 애니메이션과 같이 렌더링된 콘텐츠 또는 어떤 이 벤트에 일정하게 움직이도록 조작되어지는 게임 등에 한정 적으로 사용된다. 이를 대처하기 위한 방안으로 실제 사람 이나 동물에 센서를 부착해서 탐지하는 모션 캡쳐(Motion Capture) 방법이 이용되거나 카메라를 통해 촬영된 영상의 이미지 프로세싱을 통해 $3 \mathrm{D}$ 캐릭터와 매핑하는 광학기술이 이용되기도 하나 장소, 시간과 비용에 따른 문제점이 발생 한다[1]. 
컴퓨터상에서 모델링된 캐릭터를 애니메이션하기 위해서 는 몇 가지 방법이 필요하다. 키프레임(Key-Frame) 애니메 이션은 한 동작과 그 다음 동작을 보간법으로 연결하는 방 법이다. 그러나 이는 오랜 시간의 수작업이 필요하고 이벤 트에 대해 하나의 애니메이션을 불러오는 일대일 대응형 애 니메이션이 보편적이어서 단순한 행동이 반복되는 단점이 있다. 이를 보완하는 모션 캡쳐 애니메이션은 비교적 정확 한 모션을 추출하고 다양한 행동 애니메이션을 빠르게 생성 할 수 있으나 고가의 장치를 이용하는 비용적 부담이 있고 움직이는 몸체에 센서와 트래커를 설치해서 원하는 행동을 취해야함으로 조류나 어류와 같은 동물의 애니메이션에서는 원하는 행동정보를 추출하기가 어렵다거나 불가능 할 때가 있다. 또한 위의 두 가지 방법은 어떤 이벤트에 하나의 애 니메이션이 대응하므로 여러 요소의 애니메이션을 생성하여 보유하고 있지 않으면 입력 이벤트에 대해 출력 애니메이션 을 표현하지 못하는 경우가 생길 수도 있다. 또한 실시간 렌더링 되는 인공지능 캐릭터(NPC)의 행동을 제어하는 경 우 게임에서 사용되는 육상형 캐릭터가 주류를 이뤄 다양한 행동 및 애니메이션이 불필요하는 경우가 대부분이어서 $\mathrm{NPC}$ 의 행동을 표현하기 위해 키프레임이나 모션캡쳐를 사 용한다. 이러한 점을 해결하기 위해 본 논문에서는 실제 물 고기의 움직임을 분석하고 이를 물리법칙이나 수학적인 해 석을 통해 물고기에 특화된 애니메이션을 생성하는 절차적 애니메이션 기법을 제시한다.

\section{2. 관련 연구}

애니메이션 생성을 위한 기술을 분류하면 우선 전통적인 셀 애니메이션기법과 같이 움직임의 중요 장면들을 수작업 에 의해 생성하고 이들 사이의 중간 장면들을 보간법을 통 해 채우는 방식으로 제작되는 키프레임 애니메이션과 센서 를 통해 액터의 움직임을 입력받아 표현하는 모션캡쳐 애니 메이션, 그리고 물리법칙등 일련의 규칙들에 의해 대상체의 움직임을 자동적 또는 반자동적으로 생성하는 동작제어 애 니메이션 등이 있다[2].

\section{1 키프레임 애니메이션}

키프레임 애니메이션은 동작의 주요부분을 키프레임값을 주고 나머지 중간 부분은 키프레임을 보간하여 만들게된 다. $3 \mathrm{D}$ 상에서 캐릭터 애니메이팅 작업을 할 때 새로운 제작 환경에 접하게 되는 데 그 중 대표적인 것이 리그 구조다. 리그구조는 캐릭터의 키프레임 애니메이션 제작 시 실제 애 니메이팅 키 값이 들어가는 구조다. 즉 모델링 오브젝트 내 에 들어 있는 뼈대구조를 대신하여 선택/이동/회전등의 역 할을 수행하게 되며 이러한 수행의 결과로 애니메이션 데이 터가 생성되는 것이다. 또한 각 리그는 실제뼈대구조가 가 지고 있는 상호 유기체적인 구성요소를 그대로 표현할 수 있으므로 애니메이팅 제작에서는 빠질 수 없는 필수 요소라 할 수 있다.

\section{2 모션 캡쳐 애니메이션}

모션캡쳐는 원래 인간공학 등의 학술목적이나 재활치료 등의 의료목적에 사용되는 기구로써 고가의 가격과 한정적 인 사용범위 등으로 인해 일반인에게 널리 알려지지 않은 시스템이다. 1980년대 초기 Simon Fraser대학의 Tom Calvert교수는 통신 분압기를 인체의 양쪽 무릎에 부착하고 모션을 캡쳐하여 컴퓨터 캐릭터를 움직이는 방법을 최초로 고안하였다. 그 후 계속 발전하여 1989년부터는 점차 애니 메이션이나 뮤직 비디오, 영화, 게임 등 상업성을 띤 작품 들에 모션캡쳐 기술이 응용되기 시작하였다. 모션 캡쳐 애 니메이션은 실제 물체의 움직임을 컴퓨터에 입력해 수치적 데이터로 컴퓨터에 저장하는 것을 말한다. 간단히 과정을 살펴보면 움직임을 감지할 수 있는 센서 또는 트래커를 물 체에 부착하고, 물체가 이동할 때의 수치 데이터를 일정 간 격을 두고 저장하는 것이다. 모션캡쳐은 실시간 제어가 가 능하고 매우 복잡하거나 빠른 움직임도 자연스럽게 표현할 수 있어 최근에 방송이나 게임 제작 분야에서 가장 선호되 고 있다.

\section{3. 절차적 애니메이션 기법을 적용한 인공 물고기}

본 논문에서는 인공 물고기의 동작(Motion) 및 행동 (Behavior) 생성을 위해 다음과 같이 두 가지 구조로 정의 하였다.

- 계층 구조형 골격 설계를 통한 물고기의 단일 동작생성 ·물고기와 물고기 사이의 인터랙션을 통한 행동 생성

첫 번째는 물고기의 단일 동작 생성을 위한 골격들을 설 계하고 이 뼈대 구조의 연관관계를 두어 일정 파라미터를 통해 물고기의 동작을 생성한다. 이를 통해 꼬리의 움직임, 지느러미의 움직임, 머리 부분의 움직임과 같은 단일 동작 을 생성한다. 두 번째는 물고기들 사이의 포식과 피식 관계 에서 물고기에 센서를 두고 감지를 하여 쫓고 쫓기는 행동 을 표현한다. 이는 포식 물고기가 피식 물고기를 쫓는 행위, 피식 물고기의 회피 행위를 방향, 속도 등을 고려하여 사실 적으로 표현하기 위한 방법을 제시한다.

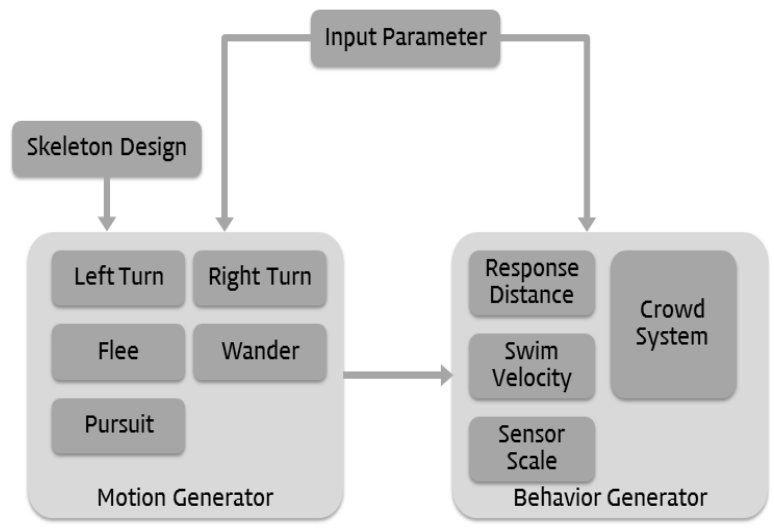

Fig. 1. Control of motion and behavior using input parameter 
3.1 인공물고기의 골격 설계 및 동작 제어

물고기의 행동이나 동작은 사람이나 육상 동물과는 달리 비교적 간단하면서 반복적 형태를 띄고 있다.[3][4] 따라서 물고기의 행동을 운동학적 분석을 통하여 물고기의 동작 패 턴을 일정한 규칙으로 모델링 할 수 있다면 이를 이용하여 실제와 유사한 동작을 생성할 수 있다. 이를 위해서는 물 고기의 동작은 비교적 단순한 수식으로 모델링 되어야 하고, 실제와 유사한 동작을 실시간으로 생성할 수 있는 알고리즘 수행 구조가 필요하다. 이러한 수행 구조에서 인공 물고기 를 전체적으로 정의하는 적은 수의 매개변수 집합을 사용하 여 매 프레임마다 절차적으로 그때그때 기하학적 모델을 계 산함으로써 절차적인 움직임 장면을 생성할 수 있다.

\section{1) 인공 물고기의 골격 모델}

인공물고기의 골격 모델은 계층적 구조로서 계층에 따라 서 세그먼트들은 조인트로 연결되어 있으며, 기본으로 깔려 있는 골격구조를 조종하여 움직임을 생성한다. 또한 움직이 는 골격에 따라서 피부의 자연스러운 연결 및 변형이 진행 될 수 있도록 구성된다. Fig. 2는 각 뼈대와 관절, 그리고 표 면의 형태를 나타낸다.

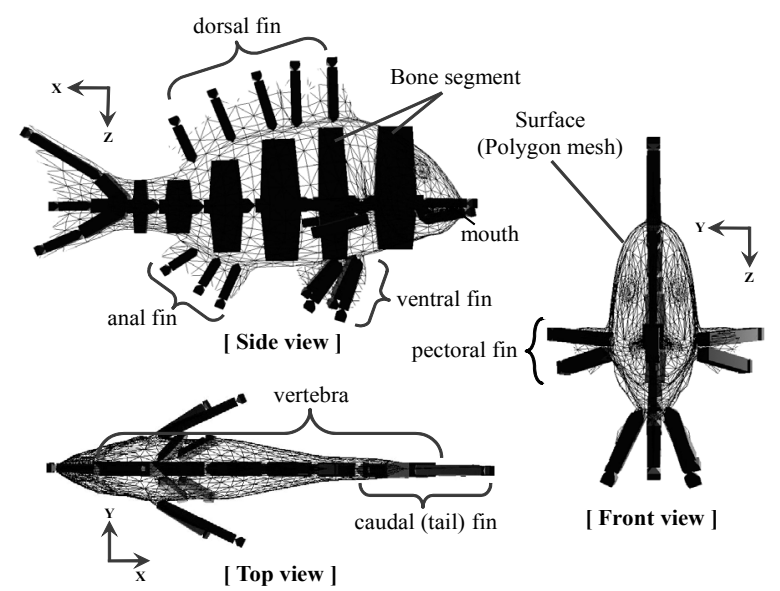

Fig. 2. Skeleton structure of artificial Fish

2) 사실적 물고기 동작의 분석

실제 물고기의 동작들은 물고기의 종류와 형태 구조에 따 라 서로 다르며 유영형태 별로는 몸에서부터 꼬리지느러미 까지 후방 추진 역동파 방향으로 구부림으로써 추진력을 얻 는 유영형태 $\mathrm{BCF}$ (Body and/or Caudal Fin)와 중간 또는 가 슴지느러미의 운동에 의해 추진력을 얻는 유영형태 $\mathrm{MPF}$ (Median and/or Paired Fin)로 분류할 수 있다. 이 중 BCF 형태가 전체 물고기의 $75 \%$ 를 차지하고 있다. 연구에서는 일 반적인 유영형태인 $\mathrm{BCF}$ 형태의 물고기를 기준으로 동작 패 턴을 분석하고, 기본적인 동작 패턴을 크게 유영동작과 회 전동작으로 구분하여 이를 중심으로 실제와 유사한 동작을 생성할 수 있도록 비교적 단순한 수식으로 동작들을 모델링 한다. 본 논문에서는 감성돔을 기반으로 인공물고기의 움직 임을 표현하는 방법을 제시한다.
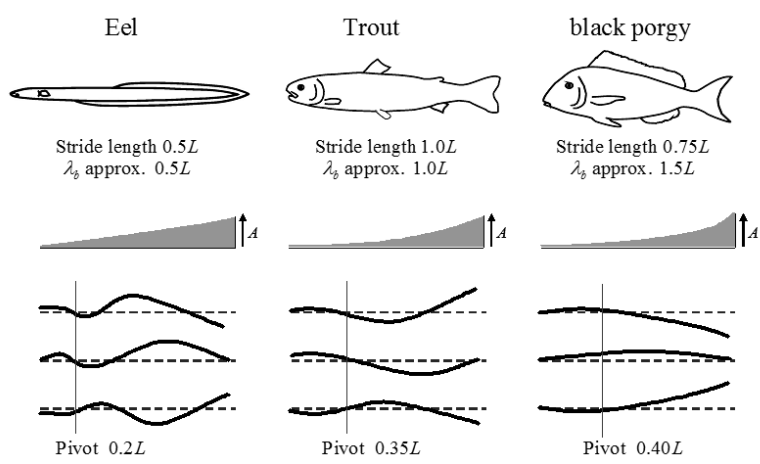

Fig. 3. Kinematic analysis of Eel, Trout, Black porgy

\section{3) 인공 물고기의 동작 생성}

유영동작과 회전동작은 몸체의 형상을 Sine곡선 형태로 생성함으로써 실제 물고기의 동작패턴과 유사한 동작을 생 성 시킬 수 있다. 즉, 인공물고기의 유영동작과 회전동작의 절차적 움직임은 골격 구조의 위치와 각도를 제어할 수 있 도록 하는 함수가 된다. 물고기 유영운동의 기초적인 Sine 진행파의 생성은 $\mathrm{Tu}$ 와 Gates[5]의 연구에서 제시된 함수를 채용하였으며 그 식은 다음과 같다.

$$
F(x, t)=A(x) \sin (2 \pi / \lambda(x-\omega t))
$$

여기서, $F$ 는 물고기 몸체의 가로 측 변위를 나타내며, $x$ 는 주축상의 관절의 위치, $t$ 는 시간, $A(x)$ 는 진폭, $\lambda$ 는 파장, $\omega$ 는 몸체의 진동수를 나타낸다.

제안된 방법에서는 물고기의 종류에 따라 달라지는 유영 형태와 각 동작에 따라 변화하는 운동의 중심점을 효과적으 로 관리하기 위해서 Pivot을 사용하였다. 뱀장어와 같이 운 동의 중심점이 비교적 앞에 있는 경우와 감성돔과 같이 운 동의 중심점이 비교적 뒤에 있는 경우 몸체에서 발생하는 파동의 진동수와 파장이 달라져 운동의 중심점이 Pivot을 통해 조절하게 된다면 다양한 종류의 운동을 발생시킬 수 있다. 또한 운동의 중심점은 물고기의 유영과 회전 시에도 변화하기 때문에 각 동작 생성 시에 Pivot을 사용한다면 운 동의 중심점을 조절한다면 좀더 자연스러운 동작을 표현할 수 있다. Fig. 4는 제안 방법의 유영 구조와 유영운동을 제 어하기 위한 파장 영역을 나타낸다.

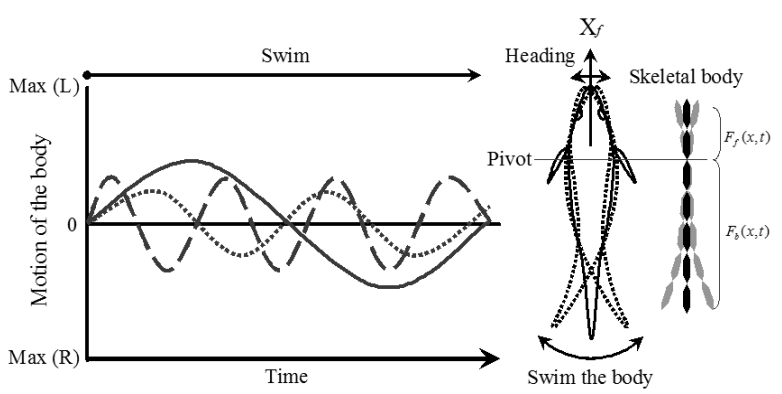

Fig. 4. Artificial Fish's swimming behavior 

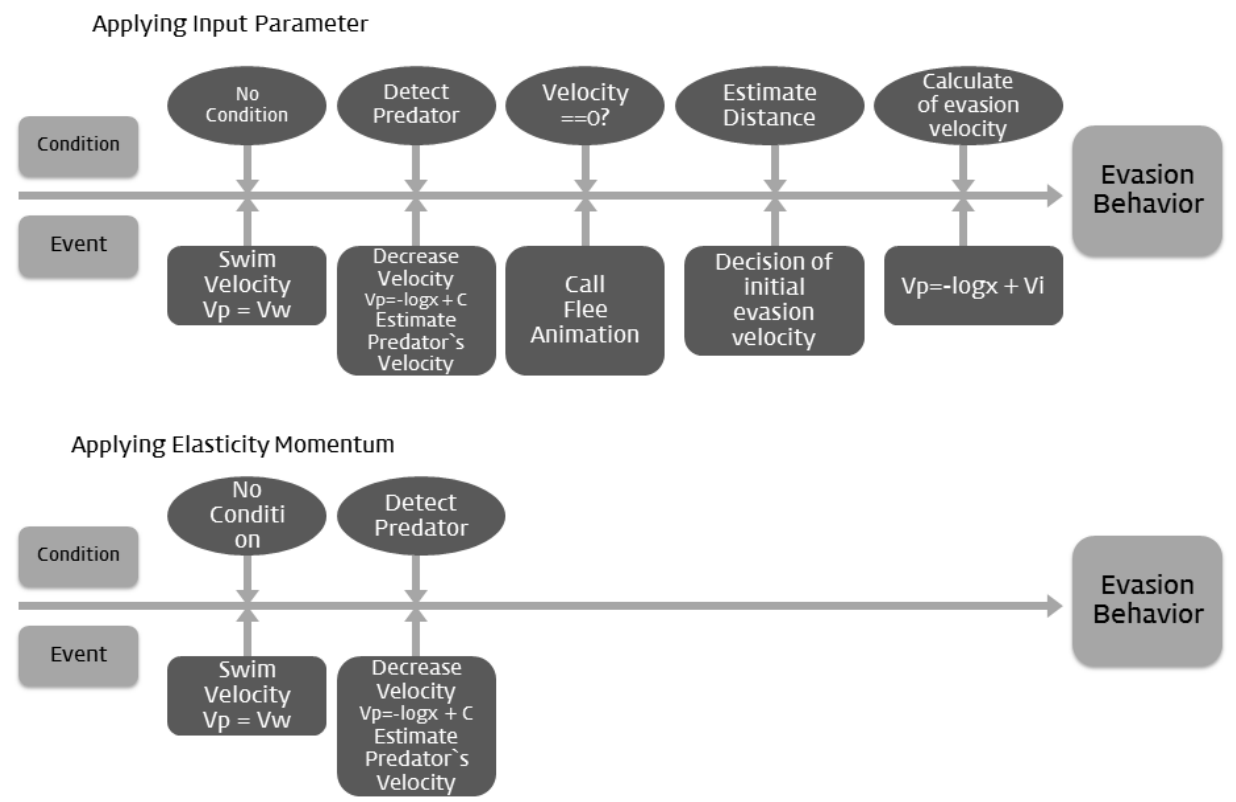

Fig. 5. Comparison of method using input parameterand method of elasticity momentum

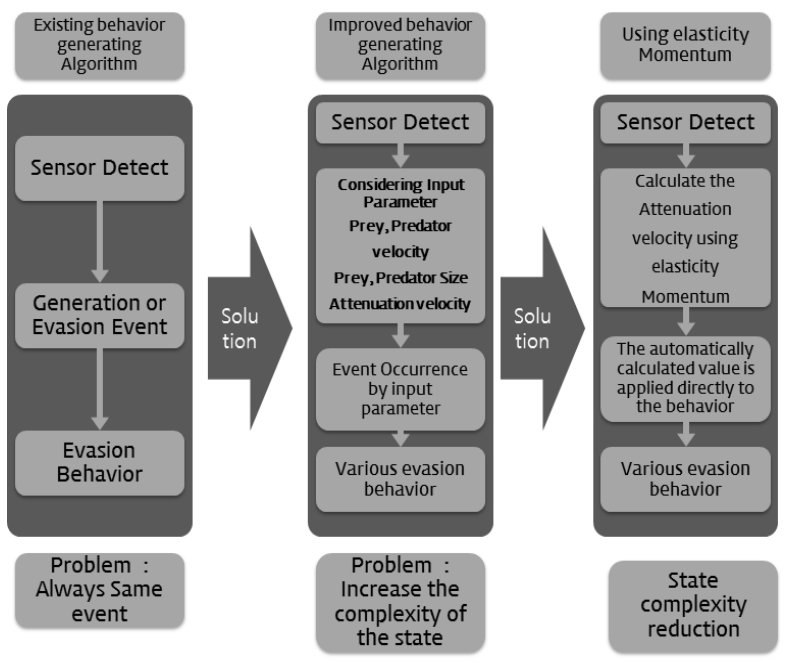

Fig. 6. Comparing the existing behavior of the algorithm and improved algorithm

\section{2 인공 물고기 사이의 인터랙션에 의한 행동 생성}

초기 인공 물고기는 포식자와 피식자 관계에서 피식자는 포식자를 감지했을 때, 센서감지, 각 객체에 맞게 정의된 행동 선택, 회피행동의 순서로 설계되었다. 이는 각 객체마 다 동일한 이벤트(센서의 감지)에 의해 동일한 행동을 유발 하여 단조로운 행동을 표현할 수밖에 없는 한계를 지니고 있다. 따라서 탄성 모멘텀을 이용한 물리학적 접근 방법을 적용하고 가변형 다중 센서를 이용하여 인공 물고기의 움 직임을 보다 사실적으로 표현할 수 있고 하나의 회피 이벤 트에 대해 다양한 행동 패턴 생성이 가능한 새로운 방법을 제시한다.

Fig. 5는 모든 입력 파라미터를 고려한 상황에서 포식자
가 피식자를 탐지했을 때의 알고리즘과 탄성 모멘텀을 적용 했을 때의 알고리즘을 비교한 것이다.

Fig. 6은 기존의 단순 행동 유발 알고리즘과 모든 입력변 수를 고려한 행동 유발 알고리즘과 본 논문에서 제시한 알 고리즘을 비교한 것이다.

\section{3 탄성 모멘텀을 적용한 인공 물고기의 행동 제어}

인공 물고기가 수중에서 받는 힘은 물고기의 추진력(관성 력), 부력, 중력, 물의 점성에 의한 마찰력 등이 있다. 본 논 문에서는 이러한 기본적인 힘에 조합과 탄성 모멘텀을 이용 해 자연스러운 행동을 생성한다. 탄성 모멘텀은 피식자와 포식자 사이의 가상의 스프링으로 생성된다. 부력과 중력은 서로 힘의 평형을 이룬다는 가정 하에 물고기가 앞으로 나 아가는 힘, 즉 관성력은 Equation (2)와 같다.

$$
F_{\text {prey- } \text { prop }}=\frac{d}{d t}\left(m_{\text {prey }} v_{\text {prey }}\right)=m_{\text {prey }} a_{\text {prey }}+\frac{d m_{\text {prey }}}{d t} v_{\text {prey }}
$$

$$
\begin{aligned}
& \cdot F_{\text {prey }}=\text { 피식자의 관성력 } \\
& \cdot a_{\text {prey }}=\text { 피식자의 가속도 } \\
& \cdot m_{\text {prey }}=\text { 피식자의 무게 } \\
& \cdot v_{\text {pery }}=\text { 피식자의 속도 }
\end{aligned}
$$

포식자의 위치를 $P_{\text {predator }}$ 라 하고 피식자의 위치를 $P_{\text {prey }}$ 라 하면 피식자와 포식자 사이의 거리는 $l$ 이 된다.

$$
\begin{aligned}
& \cdot P_{\text {predator }}=\left(x_{\text {predator }}, y_{\text {predator }}, z_{\text {predator }}\right) \\
& \cdot P_{\text {prey }}=\left(x_{\text {prey }}, y_{\text {prey }}, z_{\text {prey }}\right) \\
& \cdot l=\sqrt{\left(x_{\text {predator }}-x_{\text {pery }}\right)^{2}+\left(y_{\text {predator }}-y_{\text {pery }}\right)^{2}+\left(z_{\text {predator }}-z_{\text {pery }}\right)^{2}}
\end{aligned}
$$


피식자와 포식자의 센서의 서로 감지상태가 True가 되면 두 객체 사이에 길이가 $l$ 이고 탄성계수가 $k$ 인 스프링이 생 성된다. 이 스프링의 탄성 퍼텐셜 에너지 $V_{e}$ 는 Equation (3)과 같다.

$$
V_{e}=\int_{0}^{x} F d x=\int_{0}^{x} k x d x
$$

$F$ 는 물고기에 의한 추진력이고 $k$ 는 스프링 상수 $x$ 는 변형률을 나타낸다.

여기서 포식자의 크기는 피식자에 비해 무한히 크다고 가 정하여 고정된 격벽이라 놓는다. 이는 포식자의 이동 속도 에 의한 변형은 이루어지지 않고 피식자의 이동 속도에 의 한 변형이 이루어진다. 피식자의 추진력 $F_{p o s i t i v e}$ 에 대해 변형률 $x$ 가 생기는데 $\int_{0}^{x} k x d x=\frac{1}{2} k x^{2}$ 이므로 물고기가 스 프링에 한일 $W$ 가 에너지가 모두 탄성 포텐셜 에너지로 바뀌었으므로 변형률 $x$ 의 최대값은 $x_{\max }$ 가 된다.

$$
\begin{aligned}
& \cdot F_{\text {positive }}=m_{\text {pery }} a_{\text {pery }}-c v_{\text {pery }} \\
& \cdot W=(m a-c v) \times x \\
& \cdot \frac{1}{2} k x^{2}=\left(m_{\text {prey }} a_{\text {prey }}-c v_{p / p}\right) \times x \\
& \cdot x_{\max }=\frac{\left(c_{p / p}-m_{\text {prey }} a_{\text {prey }}\right)}{k}
\end{aligned}
$$

즉 $x$ 가 $x_{\max }$ 되었을 때 회피 이벤트를 주고, 센서 시스 템에 의해 얻어진 회피 방향은 $-\left(x_{\text {predator }}+x_{\text {obstacle }}-2 x_{\text {prey }}\right)$, $-\left(y_{\text {predator }}+y_{\text {obstacle }}-2 y_{\text {prey }}\right) .-\left(z_{\text {predator }}+z_{\text {obstacle }}-2 z_{\text {prey }}\right)$ 이 된다.

$$
\frac{1}{2} m v^{2}=\frac{1}{2} k x^{2}
$$

피식자의 초기 회피 속도 $v_{\text {escape }}$ 는 탄성 에너지가 운동 에너지로 복원된 후 속도이므로 Eq.4에 의해 $v_{\text {escape }}$ 을 구 할 수 있다.

$$
v_{\text {escape }}=\frac{\sqrt{m_{\text {prey }} k}\left(c v_{p / p}-m_{\text {prey }} a_{\text {prey }}\right)}{m_{\text {prey }} k}
$$

위를 요약하면

(1) 속도 $v_{p r e y}$ 로 움직이는 무게 $m_{\text {prey }}$ 인 피식자는 $v_{\text {predator }}$ 속도로 움직이는 포식자를 만나면 상대속도 $v_{p / p}$ 를 갖게 된다.

(2) 피식자는 회피 명령 이벤트가 일어나면 $-\left(x_{\text {predator }}+\right.$ $\left.x_{\text {obstacle }}-2 x_{\text {prey }}\right), \quad-\left(y_{\text {predator }}+y_{\text {obstacle }}-2 y_{\text {prey }}\right) . \quad-\left(z_{\text {predator }}+\right.$ $z_{\text {obstacle }}-2 z_{\text {prey }}$ ) 방향으로 회피한다.

(3) 일반적으로 포식자가 피식자의 센서(크기 : R)에 접촉했
을 때 피식자의 회피 이벤트가 일어나지만 피식자의 관성 력에 의해 $R-\frac{\left(c v_{p / p}-m_{p r e y} a_{p r e y}\right)}{k}$ 까지 접근한 후 회피 이벤트를 발생하게 된다.

(4) 초기 포식자에 대한 피식자의 회피 속도는 Equation (5) 와 같이 $v_{\text {escape }}$ 가 된다.

\section{4. 실험 및 분석}

Fig. 7은 탄성모멘텀을 적용하지 않은 상태의 피식 물고 기와 포식 물고기 사이의 인터랙션을 나타낸다. 피식 물곡 기의 센서가 포식 물고기를 탐지하는 순간 방향이 전환되고 이벤트 호출에 의해 정해진 속도로 회피하는 행동을 취한 다. 이것은 피식 물고기와 포식 물고기의 무게나 유영 속도 를 반영하지 않아 항상 같은 회피행동을 반복하게 된다.

Fig. 8은 탄성 모멘텀을 적용하여 각각의 물고기의 유영 속도에 따라 나타나는 인터랙션을 보여준다. 유영하는 물고 기의 속도와 무게에 따라 탄성력이 좌우되므로 센서에 의해
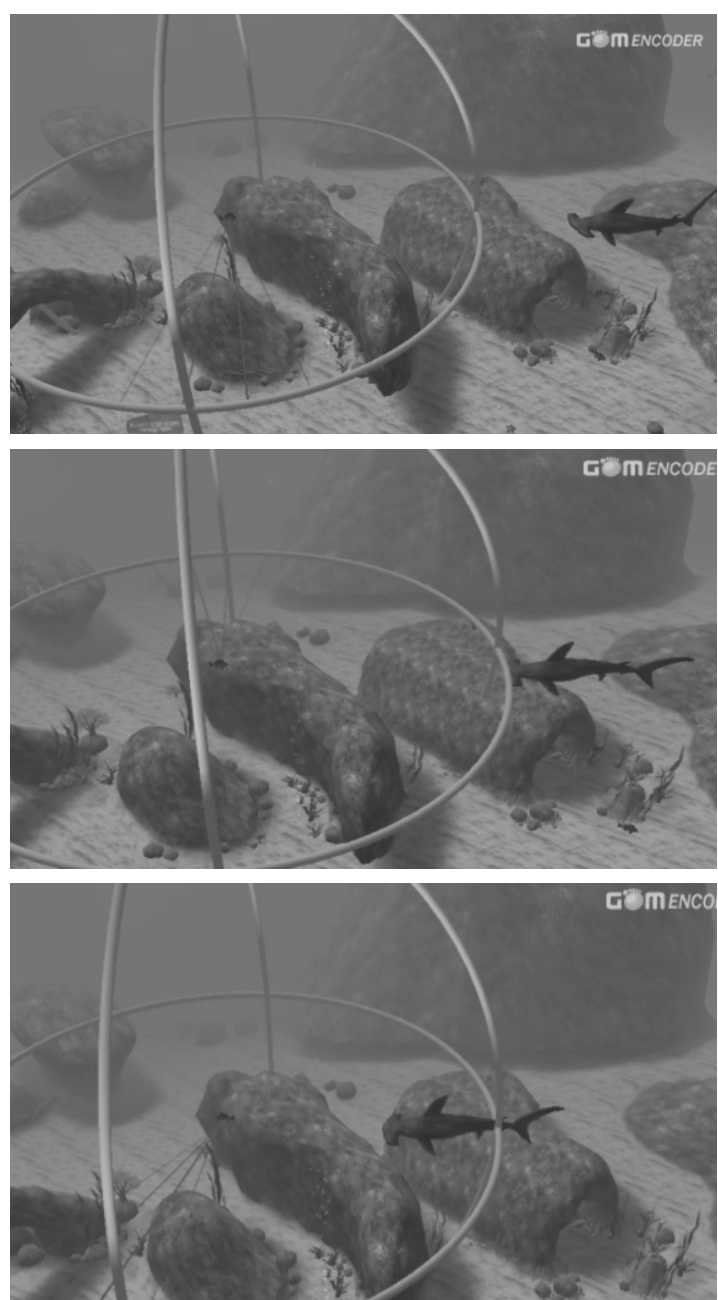

Fig. 7. Interaction does not apply to the elasticity momentum 
포식자가 감지되더라도 속도에 의한 관성력에 의해 일정 거 리만큼 더 진행되고 진행된 거리만큼 탄성력이 발생하게 된 다. 이 탄성력에 의해 초기 회피속도가 결정된다. Fig. 8의 두 번째 그림은 관성력에 의한 감쇄가 이루어지는 부분을 보여준다. 즉, 피식자는 포식자가 센서에 접촉하는 동시에 회피 이벤트를 발생하지 않고 관성력에 의해 일정 거리 만 큼 더 좁혀지게 된다. 이는 물고기의 속도에 따라 감쇄가 달리 이루어지고 초기 회피 속도도 일정하지 않고 변하게 되므로 다양한 행동을 표현할 수 있다.
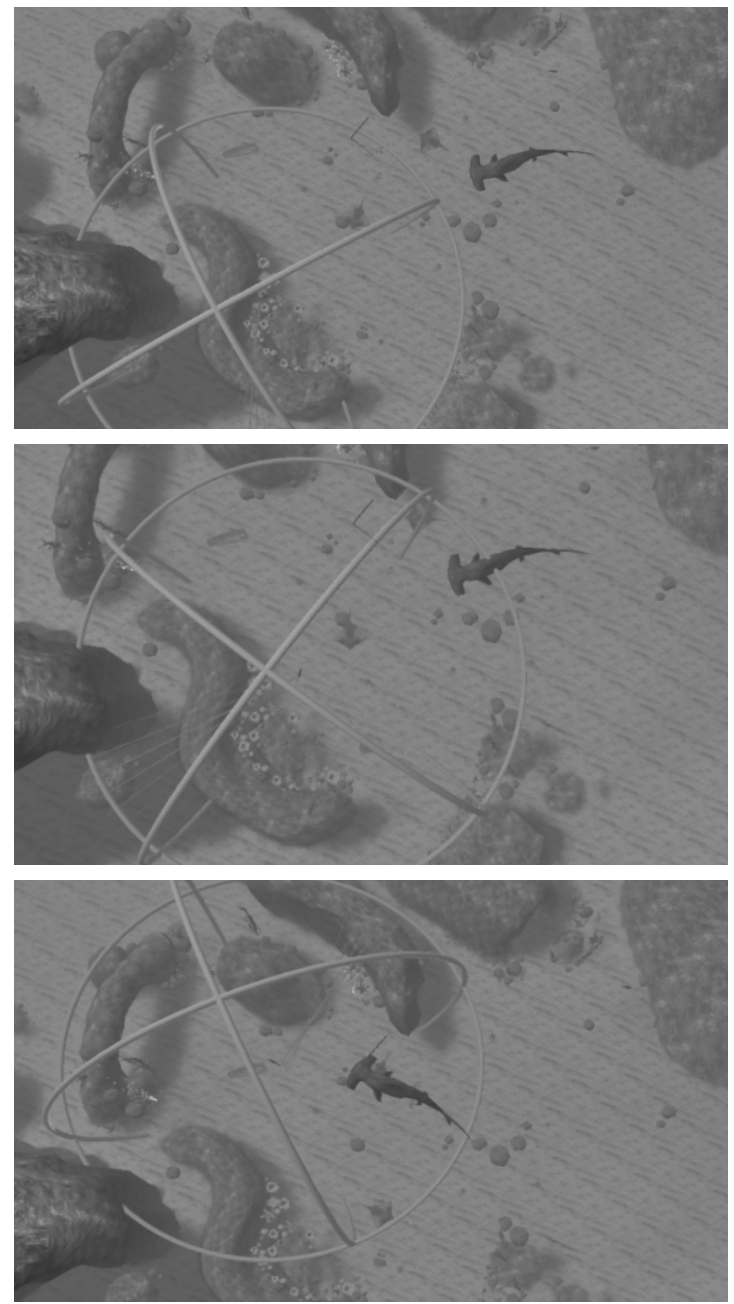

Fig. 8. Interaction apply to the elasticity momentum

Fig. 9과 Fig. 10은 기존의 탄성 모멘텀을 적용하지 않는 물고기와 탄성 모멘텀을 적용한 물고기의 속도 변화 및 방 향을 나타낸 그림이다. Fig. 9의 그래프는 시간 $t$ 에 대한 피 식자의 속도의 변화를 나타내며 $t_{6}$ 일때 포식자를 감지하여 바로 방향 전환 및 설정되어 있는 회피속도로 전환한다. 이 때 애니메이션이 자연스럽게 연결되지 않는다.

Fig. 10은 $t_{4.5}$ 에서 피식자가 포식자를 탐지한 후 관성력 에 반하는 탄성력에 의해 속도가 감쇄되고 기존의 물고기 보다 $x$ 만큼 더 포식자에게 근접한다. $x$ 가 최대값을 가질

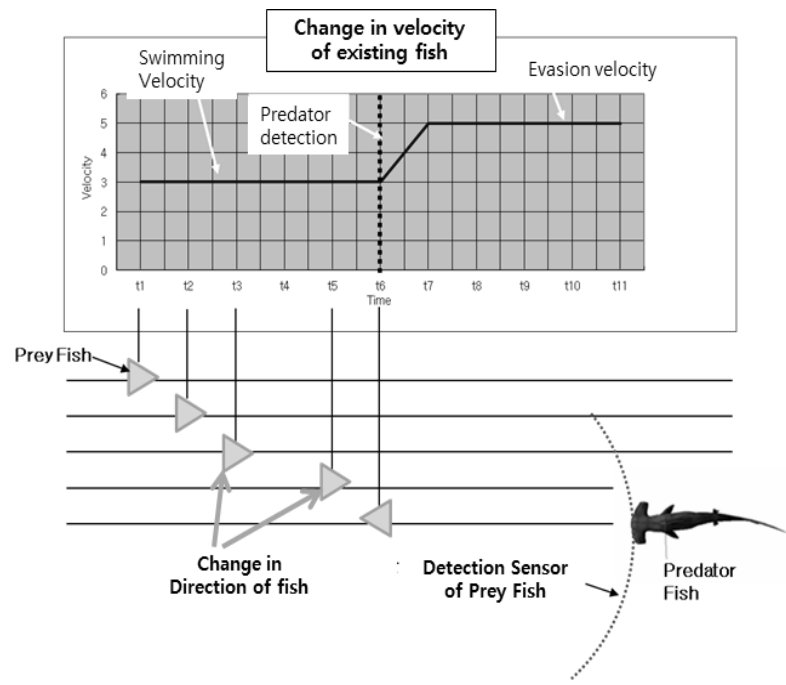

Fig. 9. Change of Speed and direction of the prey does not apply to the elasticity momentum

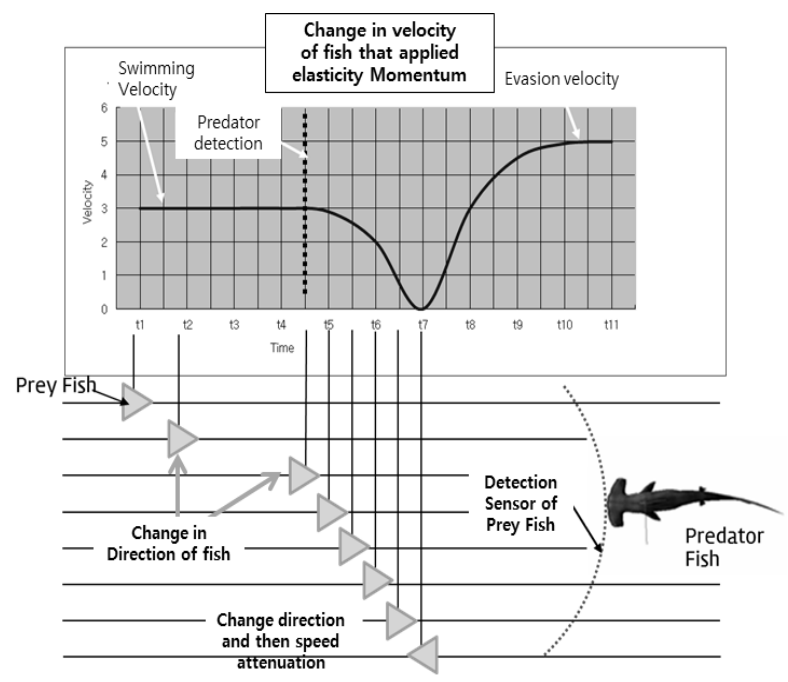

Fig. 10. Change of Speed and direction of the prey that applied the elasticity momentum

때 속도는 최소값인 0 을 갖고 반대의 회피방향을 취한다. 이때 탄성력은 최대값을 갖는다. 회피속도는 유영 속도보다 빠른 값으로 정의하였으며 같은 값을 갖게 되지만 자연스러 운 행동 표현을 위해 Equation (6)와 같이 물고기에 따른 능력치 상수값 $C_{\text {porgy }}$ 를 더하였다.

$$
v_{\text {escape }}=\frac{\sqrt{m_{\text {prey }} k}\left(a_{\text {prey }}\right)}{k}+C_{\text {porgy }}
$$

\section{5. 결론 및 향후 연구}

본 논문에서는 절차적 방법을 통해 해저 가상 공간내의 캐릭터인 인공 물고기의 동작과 행동을 효과적으로 생성하는 방법을 제안하였다. $3 \mathrm{D}$ 가상해저 콘텐츠 내에서 캐릭터들의 
사실감을 증가시키기 위해서는 물리법칙이나 수학적 해석을 통해 실시간으로 제어할 필요가 있다. 또한 빈번하게 발생되 는 이벤트에 대해 적절히 대처하여 다양한 동작을 생성하기 위해서는 시스템상의 복잡도를 줄이고 단순한 파라미터의 조 작을 통해 인공 물고기의 행동을 제어해야만 한다.

이를 위해 다음과 같은 방법을 제시하였다.

(1) 인공 물고기의 동작제어를 위한 골격 모델 제시하였고 동작 생성을 위해 복잡한 계산량을 피하고 실제 물고기의 동작 패턴에 관한 분석을 통해 실제와 유사한 동작을 생 성하도록 하였다.

(2) 인공 물고기와 또 다른 인공 물고기 사이의 상관관계 (포식과 피식) 등을 정의하고 센서 시스템을 통해 장애물 이나 포식자, 또는 피식자를 탐지할 수 있도록 설계하였 다. 또한 피식자가 포식자를 탐지 시 회피하는 과정을 탄 성력을 적용하여 자연스러운 속도 변화를 생성하도록 유 도하였다.

이 방법은 가상해저 공간의 Artificial Fish를 생성하는데 있어 긴 제작 시간이 소요되고 하나의 이벤트에 하나의 동 작을 생성해야하는 키프레임 애니메이션이나 초기 비용이 많이 소요되고 제작이 복잡할 뿐만 아니라 동작 추출 대상 이 한정되어 있는 모션캡쳐 방식의 단점을 보완할 수 있을 것이라 판단된다. 또한 움직임에 대한 규칙을 미리 정의하 고 수치적 해석에 의해 어떠한 동작이나 행동도 간단한 파 라미터의 입력을 통해 제어할 수가 있어 새로운 행동이나 동작을 생성하는데 용이하다. 이는 콘텐츠 제작 시간 및 인 력의 소요비용을 최소화하고 양질의 콘텐츠를 생산하는데 효과적일 것이다. 가상공간을 현실세계와 흡사하게 표현하 기 위해 물리적, 수치적 해석을 통해 절차적 방법으로 계산 하여 애니메이션을 생성한다면 그 범위나 규모가 무궁무진 할 것이다. 향 후 군집형 모델이 포식자를 탐지했을 때 급 격하게 변하는 행동 패턴이나 Surge를 통과할 때 그 Surge 의 속도와 군중의 유영속도 및 방향의 상관관계, 그 외 물 고기가 아닌 다른 객체 즉 해조류나 연체류 등과 같은 캐릭 터에 대한 연구가 이루어져야 할 것이다. 또한 더욱 사실적 인 Artificial Fish의 생성을 위해서는 유속이나 온도에 따른 물의 점도의 변화 등의 환경 변수뿐만 아니라 객체에 학습 상태를 이용한 향상된 인공지능에 관한 연구가 필요 할 것 이다.

\section{참 고 문 헌}

[1] Jong-Ha Lee, Character Motion Generation using Interactive Evolutionary Computation, Dept. of Computer Science, the Graduate School, Yonsei University, 2002.

[2] Seuc-Ho Ryu, Tae-Yul Kim, Byung-Pyo Kyung, "A Study about a Production of A Game Character Animation Using a Combining with a Motion-capture System", The Journal of the Korea Contents Association, Vol.5, No.5, 2005.
[3] R. L. Cook, "Stochastic sampling in computer graphics", ACM TOG, Vol.5, No.1, pp.51-72, 1986.

[4] J. W. Lee, et al., "A procedural approach to solving constraints of articulated bodies", EuroGraphics 2000, short presentations, pp.55-64, 2000.

[5] W. F. Gates, "Animation of Fish Swimming (Technical report), Department of Computer Science, University of British Columbia, 2002.

[6] C. W. Reynolds, "Flocks, Herds, and Schools: A Distributed Behavioral Model", Proceeding Computer Graphics (SIGGRAPH'87), Vol.21, No.4, pp.25-34, July, 1987.

[7] X. Tu and D. Terzopoulos, "Artificial fishes: physics, locomotion, perception, behavior", ACM SIGGRAPH 94, July, 1994.

[8] K. Hirata, Tadanori Takimoto, and Kenkichi Tamura, "Study on turning performance of a fish robot.", In Proceedings of the 1st International Symposium on Aqua Bio-Mechanisms, pp.287-292, 2000,

[9] A. Huth, C. Wissel, The simulation of movement of fish schools. J. Theoret. Biol., 156: 365-385, 1992.

[10] I. V. Kerlow, "The Art of 3-D : Computer Animation and Imaging, 2nd Edition”, John Wiley \& Sons, 2000.

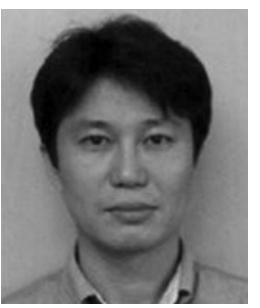

\section{김 종 한}

e-mail :chkim@dsu.ac.kr 1999년 전남대학교 기계공학과(학사)

2004년 전남대학교 소프트웨어 협동과정 (공학석사)

2004년 현 재 동신대학교 디지털콘텐츠 협동연구센터 선임연구원, 전남대

학교 전산학과 박사과정

관심분야: 소프트웨어공학, 가상현실, 인공지능, 정형기법

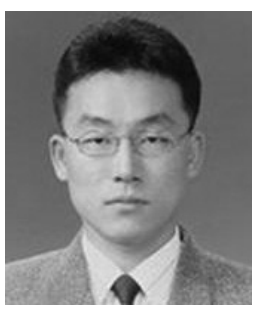

\section{윤 재 홍}

e-mail : jhyoun@dsu.ac.kr

2005년 동신대학교 컴퓨터학과(이학박사)

2006년 2009년 동신대학교 디지털콘텐츠 학과 교수

2009년 현 재 동신대학교 디지털콘텐츠 협동연구센터 부장

관심분야: $3 \mathrm{D}$ 입체영상, 실감콘텐츠, 정보통신 


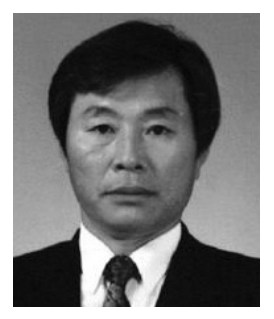

\section{김 병 기}

e-mail : bgkim@jnu.ac.kr

1978년 전남대학교 수학과(이학사)

1980년 전남대학교 수학과(이학석사)

2000년 전북대학교 수학과(이학박사)

1981년 현 재 전남대학교 전자컴퓨터

$$
\text { 공학부 교수 }
$$

관심분야: 소프트웨어공학, 객체지향시스템 등 